\title{
Parallel labeling experiments validate Clostridium acetobutylicum metabolic network model for ${ }^{13} \mathrm{C}$ metabolic flux analysis
}

Jennifer Au, Jungik Choi, Shawn W. Jones, Keerthi P. Venkataramanan, Maciek R. Antoniewicz*

Department of Chemical and Biomolecular Engineering, Metabolic Engineering and Systems Biology Laboratory, University of Delaware, Newark DE 19716, USA

*corresponding author:

Maciek R. Antoniewicz

Department of Chemical and Biomolecular Engineering

University of Delaware

150 Academy St

Newark, DE 19716

Tel.: 302-831-8960

Fax.: 302-831-1048

Email:mranton@udel.edu 


\section{ABSTRACT}

In this work, we provide new insights into the metabolism of Clostridium acetobutylicum ATCC 824 obtained using a systematic approach for quantifying fluxes based on parallel labeling experiments and ${ }^{13} \mathrm{C}$-metabolic flux analysis $\left({ }^{13} \mathrm{C}\right.$-MFA). Here, cells were grown in parallel cultures with [1$\left.{ }^{13} \mathrm{C}\right]$ glucose and $\left[\mathrm{U}-{ }^{13} \mathrm{C}\right]$ glucose as tracers and ${ }^{13} \mathrm{C}-\mathrm{MFA}$ was used to quantify intracellular metabolic fluxes. Several metabolic network models were compared: an initial model based on current knowledge, and extended network models that included additional reactions that improved the fits of experimental data. While the initial network model did not produce a statistically acceptable fit of ${ }^{13} \mathrm{C}$-labeling data, an extended network model with five additional reactions was able to fit all data with 292 redundant measurements. The model was subsequently trimmed to produce a minimal network model of C. acetobutylicum for ${ }^{13} \mathrm{C}-\mathrm{MFA}$, which could still reproduce all of the experimental data. The flux results provided valuable new insights into the metabolism of C. acetobutylicum. First, we found that TCA cycle is effectively incomplete, as there was no measurable flux between $\alpha$ ketoglutarate and succinyl-CoA, succinate and fumarate, and malate and oxaloacetate. Second, an active pathway was identified from pyruvate to fumarate via aspartate. Third, we found that isoleucine was produced exclusively through the citramalate synthase pathway in C. acetobutylicum and that CAC3174 was likely responsible for citramalate synthase activity. These model predictions were confirmed in several follow-up tracer experiments. The validated metabolic network model established in this study can be used in future investigations for unbiased ${ }^{13} \mathrm{C}$-flux measurements in C. acetobutylicum.

\section{KEYWORDS}

Network model validation; ${ }^{13} \mathrm{C}$ flux analysis; statistical analysis; mass spectrometry; isotopic tracers. 


\section{INTRODUCTION}

In recent decades, fluctuating oil prices, diminishing fossil fuel supplies, and concerns about climate change have prompted demand for alternative energy sources (Stephanopoulos, 2008). Considerable effort has gone into research and development of microbial biofuel production from biomass (Stephanopoulos, 2007). Due to their wide substrate range, solventogenic clostridia are seen as a promising class of organisms for biofuel production (Tracy et al., 2012). Clostridium acetobutylicum, in particular, was historically used for industrial-scale acetone-butanol-ethanol (ABE) fermentation and may potentially play a role in butanol production today (Durre, 1998). Research on the genetics and metabolic engineering of this model organism may also lead to its use in new industrial processes for the production of butyric acid, butanediol, propanol, acetoin, and biohydrogen (Papoutsakis, 2008; Tracy et al., 2012).

Although the biochemistry of $C$. acetobutylicum has been extensively reviewed (Nolling et al., 2001; Papoutsakis, 1984; Paredes et al., 2005), the central metabolic pathways remain only partially resolved for this organism (Crown et al., 2011). As an example, two recent reconstructions of genome-scale models for C. acetobutylicum (Lee et al., 2008; Senger and Papoutsakis, 2008) have proposed different mechanisms for the biosynthesis of $\alpha$-ketoglutarate, the precursor for glutamate, glutamine and proline. One model posed the production of glutamate via the urea cycle and arginine biosynthesis pathway operating in the reverse direction (Senger and Papoutsakis, 2008), while the other suggested a reductive TCA cycle operating in the direction from oxaloacetate to fumarate and to $\alpha$-ketoglutarate (Lee et al., 2008). Recently, stable-isotope labeling experiments and qualitative ${ }^{13} \mathrm{C}$ isotopomer analysis have lent new insights into C. acetobutylicum metabolism. Two studies supported the idea of an incomplete TCA cycle and suggested a $R e$-stereospecificity for the citrate synthase reaction (Amador-Noguez et al., 2010; Crown et al., 2011). Another study suggested that the 
TCA cycle was bifurcated with an oxidative and reductive branch resulting in the excretion of succinate as a dead-end product (Amador-Noguez et al., 2011).

In this work, we have quantitatively elucidated central metabolism of C. acetobutylicum using ${ }^{13} \mathrm{C}$ metabolic flux analysis $\left({ }^{13} \mathrm{C}-\mathrm{MFA}\right)$, the powerful method for determining intracellular metabolic fluxes in living cells (Antoniewicz, 2013a; Crown and Antoniewicz, 2013a). In contrast with previous qualitative studies, here we used the power of parallel labeling experiments and rigorous statistical analysis (Antoniewicz, 2013d) to conclusively establish the structure of central metabolic pathways and the direction of carbon flow in the TCA cycle and through amino acid biosynthesis pathways in C. acetobutylicum. Contrary to previously proposed hypotheses, we find that while the TCA cycle runs in the oxidative direction, there is no notable flux between $\alpha$-ketoglutarate and succinyl-CoA or succinate and fumarate, and that the conversion of succinyl-CoA to succinate proceeds independently of the TCA cycle. We also show that there is no flux between malate and oxaloacetate. Additionally, we identified a pyruvate-to-fumarate pathway that proceeds via aspartate. Finally, we identified a putative citramalate synthase gene that is the first step in the biosynthesis of isoleucine in $C$.

acetobutylicum. This work illustrates the power of ${ }^{13} \mathrm{C}-\mathrm{MFA}$ and parallel labeling experiments in validating metabolic network models and quantifying accurate metabolic fluxes. The systematic approach employed here can be easily applied to elucidate the metabolism of other poorly understood organisms (Swarup et al., 2014; Tang et al., 2012; Tang et al., 2009).

\section{MATERIALS AND METHODS}

\subsection{Materials}

Media and chemicals were purchased from Sigma-Aldrich (St. Louis, MO). $\left[1-{ }^{13} \mathrm{C}\right]$ Glucose $(99.5 \%$

${ }^{13} \mathrm{C}$ ) and $\left[\mathrm{U}-{ }^{13} \mathrm{C}\right]$ glucose $\left(99.2 \%{ }^{13} \mathrm{C}\right.$ ) (Antoniewicz et al., 2011) were purchased from Cambridge 
Isotope Laboratories (Andover, MA). $\left[4-{ }^{13} \mathrm{C}\right]$ Asparate $\left(99 \%{ }^{13} \mathrm{C}\right)$, $\left[\mathrm{U}-{ }^{13} \mathrm{C}\right]$ fumarate $\left(99 \%{ }^{13} \mathrm{C}\right)$ and $[1-$ $\left.{ }^{13} \mathrm{C}\right]$ serine $\left(99.0 \%{ }^{13} \mathrm{C}\right.$ ) were purchased from Isotec (St. Louis, MO). The defined clostridial growth medium (CGM) contained per liter of medium: $0.75 \mathrm{~g} \mathrm{KH}_{2} \mathrm{PO}_{4}, 0.98 \mathrm{~g} \mathrm{~K}_{2} \mathrm{HPO}_{4} \cdot 3 \mathrm{H}_{2} \mathrm{O}, 1.0 \mathrm{~g} \mathrm{NaCl}$, $3.3 \mathrm{~g}$ ammonium acetate, $0.05 \mathrm{~g} \mathrm{CaCl}_{2} \cdot 2 \mathrm{H}_{2} \mathrm{O}, 0.35 \mathrm{~g} \mathrm{MgSO}_{4}, 0.01 \mathrm{MnSO}_{4} \cdot \mathrm{H}_{2} \mathrm{O}, 0.01 \mathrm{~g} \mathrm{FeSO}_{4} \cdot 7 \mathrm{H}_{2} \mathrm{O}$, $0.004 \mathrm{~g}$ PABA, $0.00001 \mathrm{~g}$ biotin, and 20 to $40 \mathrm{~g}$ glucose.

\subsection{Strain and growth conditions}

C. acetobutylicum ATCC 824 (American Type Culture Collection, Manassas, VA) was stored at $85^{\circ} \mathrm{C}$ in CGM medium containing $15 \%$ glycerol. For the pre-culture, a single colony of $C$. acetobutylicum from CGM agar plate was inoculated into a culture tube containing $10 \mathrm{~mL}$ of CGM. Cells were then grown anaerobically at $37^{\circ} \mathrm{C}$ in an anaerobic chamber (Forma, Thermo Scientific) to an optical density $\left(\mathrm{OD}_{600}\right)$ of $0.5-1.0$. About $0.5 \mathrm{~mL}$ of this culture was then used to inoculate $10 \mathrm{~mL}$ of fresh CGM with $20 \mathrm{~g} / \mathrm{L}$ glucose, i.e. 5\% (v/v) inoculum fraction. Four cultures were inoculated at the same time, which were then transferred to mini-bioreactors that were custom-constructed using 15-mL anaerobic Hungate tubes (Bellco Glass Cat. No. 2047-16125). Each culture tube had a screw cap with a rubber septum that was pierced by three needles for: (1) supply of filter-sterilized $\mathrm{N}_{2}$ (injected into the head space at $5 \mathrm{~mL} / \mathrm{min}$ to maintain anaerobic growth conditions); (2) sampling of the cell culture; and (3) venting of off-gasses. The mini-bioreactors were autoclaved prior to inoculation. Gas flow rates were monitored by a digital flowmeter (Supelco, Veri-Flow 500). The temperature of cultures was maintained at $37^{\circ} \mathrm{C}$ by placing the tubes in a heating block (J-KEM Parallel Bioreactor System, PRS-120R), and mixing in the mini-bioreactors was achieved using a magnetic stirring bar. 
After inoculation, the four parallel cultures were grown for $6.5 \mathrm{~h}$, when a bolus of $\left[\mathrm{U}_{-}{ }^{13} \mathrm{C}\right] \mathrm{glucose}(20$ wt $\%$ solution) was added to two of the cultures, and a bolus of $\left[1-{ }^{13} \mathrm{C}\right]$ glucose $(20 \mathrm{wt} \%$ solution) was added to the other two cultures. The resulting concentration of ${ }^{13} \mathrm{C}$-labeled glucose in each culture vessel was approximately $20 \mathrm{~g} / \mathrm{L}$ (i.e. $~ 50 \%$ unlabeled glucose and $\sim 50 \%{ }^{13} \mathrm{C}$-labeled glucose). The cultures were then grown for another 3 h. At 9.5 h, cells were harvested by centrifugation and used for subsequent GC-MS analysis. In the follow-up tracer experiments with $\left[\mathrm{U}-{ }^{13} \mathrm{C}\right]$ fumarate and $[1$ $\left.{ }^{13} \mathrm{C}\right]$ serine, cells were first grown on medium without ${ }^{13} \mathrm{C}$-tracers until early exponential growth phase. Next, a bolus of $\left[\mathrm{U}_{-}{ }^{13} \mathrm{C}\right]$ fumarate or $\left[1-{ }^{13} \mathrm{C}\right]$ serine was added to a final concentration of $4 \mathrm{mM}$ [U- $\left.{ }^{13} \mathrm{C}\right]$ fumarate or $2 \mathrm{mM}\left[1-{ }^{13} \mathrm{C}\right]$ serine. The cells were then grown for another $8 \mathrm{~h}$, at which point cellular metabolism was quenched by placing the culture tubes in $-20{ }^{\circ} \mathrm{C}$ freezer for 10 minutes, and cells intracellular metabolites were extracted. In the follow-up tracer experiment with $\left[4-{ }^{13} \mathrm{C}\right]$ aspartate cells inoculated into medium that contained $6 \mathrm{mM}$ of $\left[4-{ }^{13} \mathrm{C}\right]$ aspartate in addition to glucose. After an overnight incubation, metabolism was quenched at $-20{ }^{\circ} \mathrm{C}$ and cells were harvested by centrifugation and used for subsequent intracellular metabolite extraction (Amador-Noguez et al., 2010) and GCMS analysis.

\subsection{Analytical methods}

Medium samples were collected at multiple time points during the culture to monitor cell growth, glucose consumption, and product accumulation. Optical density at $600 \mathrm{~nm}\left(\mathrm{OD}_{600}\right)$ was measured using a spectrophotometer (Eppendorf BioPhotometer). The $\mathrm{OD}_{600}$ values were converted to cell dry weight concentrations using a pre-determined $\mathrm{OD}_{600}$-dry cell weight relationship $\left(1.0 \mathrm{OD}_{600}=0.26\right.$ $\left.\mathrm{g}_{\mathrm{DW}} / \mathrm{L}\right)$. After centrifugation, the supernatant was separated from the biomass pellet and glucose concentration in the supernatant was determined by YSI 2700 biochemistry analyzer (YSI, Yellow 
Springs, $\mathrm{OH})$. Concentrations of acetate, butyrate, acetoin, acetone, butanol, and ethanol in the supernatant were determined using an Agilent 1200 Series HPLC (Tomas et al., 2003).

\subsection{Gas chromatography-mass spectrometry}

GC-MS analysis of ${ }^{13} \mathrm{C}$-labeling was performed on an Agilent 7890A GC system equipped with a DB-5MS capillary column (30 m, 0.25 mm i.d., $0.25 \mu$ m-phase thickness; Agilent J\&W Scientific), connected to a Waters Quattro Micro Tandem Mass Spectrometer (GC-MS/MS) operating under ionization by electron impact (EI) at $70 \mathrm{eV}$. GC-MS analysis of tert-butyldimethylsilyl (TBDMS) derivatized proteinogenic amino acids was performed as described by (Leighty and Antoniewicz, 2012). GC-MS analysis of TBDMS derivatized intracellular metabolites was performed as described by (Ahn and Antoniewicz, 2011). Mass isotopomer distributions were obtained by integration (Antoniewicz et al., 2007a) and corrected for natural isotope abundances (Fernandez et al., 1996).

\subsection{Metabolic network model}

An initial metabolic network model of C. acetobutylicum metabolism was constructed for ${ }^{13}$ C-MFA based on available genome scale models (Lee et al., 2008; Senger and Papoutsakis, 2008) and annotated metabolic pathway databases (Caspi et al., 2012; Kanehisa and Goto, 2000; Kanehisa et al., 2012). In addition, an extended network model was constructed that included additional reactions that were found to improve the fits of ${ }^{13} \mathrm{C}$-labeling data. Finally, a minimal network model was constructed after removing all reactions from the extended model that were determined to carry no

measurable flux. The minimal model was confirmed to produce a statistically acceptable fit of all ${ }^{13} \mathrm{C}$ labeling data in this study. All three models are provided in Appendix A.

\section{6. ${ }^{13}$ C-Metabolic flux analysis}


${ }^{13}$ C-MFA was performed using the Metran software (Yoo et al., 2008), which is based on the elementary metabolite units (EMU) framework (Antoniewicz et al., 2007b; Young et al., 2008). Fluxes were estimated by minimizing the variance-weighted sum of squared residuals (SSR) between the experimentally measured and model predicted metabolite yields for acetate, butyrate, acetoin, acetone, butanol, ethanol, and biomass, and mass isotopomer distributions of protein-bound amino acids using non-linear least-squares regression (Antoniewicz et al., 2006). Metabolite yields were expressed as mol product produced / 100 mol glucose consumed, and glucose uptake was fixed at 100 (Crown and Antoniewicz, 2013b). For combined analysis of parallel labeling experiments, multiple data sets were fitted simultaneously to a single flux model, as described previously (Leighty and Antoniewicz, 2012). In all cases, flux estimation was repeated at least 10 times starting with random initial values for all fluxes to find a global solution. At convergence, accurate $95 \%$ confidence intervals were computed for all estimated fluxes by evaluating the sensitivity of the minimized SSR to flux variations (Antoniewicz et al., 2006). Precision of estimated fluxes was determined as follows (Antoniewicz et al., 2006):

Flux precision $($ stdev $)=[($ flux upper bound $95 \%)-($ flux lower bound $95 \%)] / 4$

To model fractional labeling of glucose in the medium (i.e. only about $50 \%$ of glucose in the medium was ${ }^{13}$ C-labeled), a D-value parameter was included in ${ }^{13} \mathrm{C}$-MFA (Antoniewicz et al., 2007c). To model fractional labeling of biomass amino acids, G-value parameters were also included in ${ }^{13} \mathrm{C}$ MFA (Antoniewicz et al., 2007c). As described previously, a G-value represents the fraction of a metabolite pool that is produced during the labeling period (i.e. in this case between $6.5 \mathrm{~h}$ and $9.5 \mathrm{~h}$ ), while 1-G represents the fraction of naturally labeled biomass that was present prior to the addition of tracers. One G-value parameter was included for each measured amino acid in each data set 
(Antoniewicz et al., 2007c; Leighty and Antoniewicz, 2012). Reversible reactions were modeled as separate forward and backward fluxes. Net and exchange fluxes were determined as follows: $\mathrm{v}_{\text {net }}=\mathrm{v}_{\mathrm{f}^{-}}$ $\mathrm{v}_{\mathrm{b}} ; \mathrm{v}_{\mathrm{exch}}=\min \left(\mathrm{v}_{\mathrm{f}}, \mathrm{v}_{\mathrm{b}}\right)$.

\subsection{Goodness-of-fit analysis}

To determine the goodness-of-fit, ${ }^{13} \mathrm{C}$-MFA fitting results were subjected to a $\chi^{2}$-statistical test. In short, assuming the network model is correct and data are without gross measurement errors, the minimized SSR is a stochastic variable with a $\chi^{2}$-distribution. The number of degrees of freedom is equal to the number of fitted measurements $n$ minus the number of estimated independent parameters $p$. The acceptable range of SSR values is between $\chi_{\alpha / 2}^{2}(n-p)$ and $\chi_{1-\alpha / 2}^{2}(n-p)$, where $\alpha$ is a certain chosen threshold value, for example 0.05 for $95 \%$ confidence interval (Antoniewicz et al., 2006). Fits with a minimized SSR above the threshold value were considered statistically not acceptable.

\section{RESULTS AND DISCUSSION}

\subsection{Parallel labeling experiments}

C. acetobutylicum ATCC 824 was grown anaerobically in four parallel cultures at $37^{\circ} \mathrm{C}$ on defined medium with $20 \mathrm{~g} / \mathrm{L}$ glucose and $40 \mathrm{mM}$ acetate. Acetate served here as a buffer to prevent large $\mathrm{pH}$ drops that would inhibit cell growth. Cells were inoculated at an optical density $\left(\mathrm{OD}_{600}\right)$ of approximately 0.05 . After $6.5 \mathrm{~h}$, a bolus of ${ }^{13} \mathrm{C}$-labeled glucose was added. Two cultures received a bolus of $20 \mathrm{~g} / \mathrm{L}\left[\mathrm{U}-{ }^{13} \mathrm{C}\right] \mathrm{glucose}$, and two cultures received a bolus of $20 \mathrm{~g} / \mathrm{L}\left[1-{ }^{13} \mathrm{C}\right] \mathrm{glucose}$. The cells were then grown for an additional $3 \mathrm{~h}$ in the presence of the ${ }^{13} \mathrm{C}$-tracers, and at $9.5 \mathrm{~h}$ the cells were harvested by centrifugation for subsequent GC-MS analysis. The final $\mathrm{OD}_{600}$ of the parallel cultures was $1.5 \pm 0.3$. Over the course of the experiment the cells produced about $4 \mathrm{mM}$ acetic acid and 9 mM butyric acid. Only very low concentrations of solvents were detected by HPLC (acetoin, acetone, 
butanol, and ethanol were less than $1 \mathrm{mM}$ ), indicating that the cells were still in the acetogenic growth phase.

\subsection{Gas chromatography-mass spectrometry analysis}

Isotopic labeling of biomass amino acids was determined by GC-MS for ${ }^{13} \mathrm{C}-\mathrm{MFA}$, after hydrolysis of biomass and TBDMS derivatization of the amino acids. The measured mass isotopomer distributions (MIDs) of 22 amino acid fragments are given in Supplementary Materials. There was good agreement between the measured MIDs for the two biological replicates for each isotopic tracer. The average difference between the measured mass isotopomer abundances for $\left[\mathrm{U}_{-}{ }^{13} \mathrm{C}\right] \mathrm{glucose}$ experiments was $0.15 \mathrm{~mol} \%$, and the average difference for $\left[1-{ }^{13} \mathrm{C}\right]$ glucose experiments was 0.14 mol\%. This good agreement confirms that biological variability between the four labeling experiments was small, which is important since good biological reproducibility is a strict requirement for combined flux analysis of parallel labeling experiments (Crown and Antoniewicz, 2013a; Leighty and Antoniewicz, 2013).

\section{3. ${ }^{13} \mathrm{C}$-Metabolic flux analysis and network model validation}

A detailed metabolic network model of $C$. acetobutylicum metabolism was constructed for ${ }^{13} \mathrm{C}-\mathrm{MFA}$ based on two available genome-scale models and reactions annotated in KEGG and BioCyc databases. The base model (86 reactions, Appendix A) included all major metabolic pathways of central carbon metabolism, lumped amino acid biosynthesis pathways, and a lumped reaction for cell growth. When ${ }^{13}$ C-MFA was performed with this base model, however, we did not obtain statistically acceptable fits for the $\left[\mathrm{U}_{-}{ }^{13} \mathrm{C}\right]$ glucose data, $\left[1-{ }^{13} \mathrm{C}\right]$ glucose data, and combined analysis of all four parallel labeling experiments. The weighted sum of squared residuals (SSR) values were more than 10-fold higher than statistically acceptable given the number of redundant measurements (Table 1). 
Inspection of the residuals between the measured and predicted mass isotopomers revealed that the largest residuals were due to poor fits of leucine and isoleucine mass isotopomers, which are produced from acetyl-CoA and pyruvate. To improve the fits of leucine, we added a reaction to the model that accounted for dilution of intracellular acetyl-CoA pool by extracellular unlabeled acetate $\left(\mathrm{v}_{91}\right)$. It was previously reported that extracellular acetate can dilute the labeling of intracellular acetyl-CoA pool by up to 20\% (Amador-Noguez et al., 2010). Indeed, we found that the addition of this flux significantly improved the fits of leucine labeling data; however, isoleucine mass isotopomers still contributed to large SSR values. In the base model, isoleucine was produced from aspartate as proposed by Senger and Papoutsakis (2008). However, there are two alternative pathways for isoleucine biosynthesis known: one from threonine and a second from pyruvate and acetyl-CoA via citramalate synthase (Wu et al., 2010). Both pathways were added to the model (lumped reactions $\mathrm{v}_{64}$ and $\mathrm{v}_{66}$ ). The addition of these reactions resulted in significant improvements in the fits of isoleucine labeling data.

With this updated model, $\left[1{ }^{13} \mathrm{C}\right]$ glucose data was fitted adequately (Table 1 ). However, the model still did not produce acceptable fits for $\left[\mathrm{U}_{-}{ }^{13} \mathrm{C}\right] \mathrm{glucose}$ data, and for combined analysis of all four data sets. Inspection of the residuals revealed that the largest residuals were now due to poor fits of alanine and valine mass isotopomers in the $\left[\mathrm{U}-{ }^{13} \mathrm{C}\right] \mathrm{glucose}$ data sets. This indicated that pyruvate labeling was not correctly described by the model. Specifically, the relatively high abundances of M+1 and M+2 isotopomers of alanine were unexpected. Previously, Amador-Noguez et al. (2010) identified a similar discrepancy in their data, which was resolved by assuming a reversible pyruvate ferredoxin oxidoreductase (PFOR) reaction. It was proposed that the PFOR reaction should be modeled as a two-step process, consisting of a first reversible step that exchanges $\mathrm{C} 1$-atom of 
pyruvate with intracellular $\mathrm{CO}_{2}$, and a second irreversible step that produces acetyl-CoA. A similar mechanism was also proposed for the PFOR reaction in the related organism Clostridium thermoaceticum (Furdui and Ragsdale, 2000). When we added this two-step PFOR reaction to our

model $\left(\mathrm{v}_{21}\right)$, the fits were indeed significantly improved, especially for $\left[\mathrm{U}^{-13} \mathrm{C}\right] \mathrm{glucose}$ data; however, combined analysis of all four data sets still did not produce a statistically acceptable fit (Table 1). Now, the largest residuals were due to aspartate, threonine, and glutamate mass isotopomers. Previously, we observed a similar discrepancy in these amino acids when validating the metabolic network model for E. coli (Leighty and Antoniewicz, 2012; Leighty and Antoniewicz, 2013). In that case, the discrepancy was resolved by adding a dilution flux for intracellular $\mathrm{CO}_{2}$ pool from unlabeled $\mathrm{CO}_{2}$ sources. To test if a similar dilution of intracellular $\mathrm{CO}_{2}$ could be occurring in $C$. acetobutylicum, we added the same $\mathrm{CO}_{2}$ dilution reaction to the model $\left(\mathrm{v}_{90}\right)$. With this extended model we finally obtained a statistically acceptable fit of all data, including combined analysis of all four data sets (Table 1).

\subsection{Minimal network model}

Next, we set out to establish a minimal network model of $C$. acetobutylicum metabolism that could still produce an acceptable fit of all ${ }^{13} \mathrm{C}$-labeling data. A validated minimal model of $C$.

acetobutylicum would be a valuable resource for future ${ }^{13} \mathrm{C}-\mathrm{MFA}$ studies. For this purpose, we evaluated the $95 \%$ confidence intervals of the estimated metabolic fluxes in the extended model. We identified 12 fluxes that were determined to carry no flux, defined here as fluxes for which the $95 \%$ confidence interval included zero flux value. The following fluxes were identified as insignificant: oxidative pentose phosphate pathway fluxes $\left(\mathrm{v}_{9}, \mathrm{v}_{10}=0.00 \pm 0.04\right)$; Entner-Doudoroff pathway fluxes $\left(\mathrm{v}_{18}, \mathrm{v}_{19}=0.00 \pm 0.05\right)$; flux from $\alpha$-ketoglutarate to succinyl-CoA $\left(\mathrm{v}_{26}=0.0 \pm 0.1\right)$; flux from succinate to fumarate $\left(\mathrm{v}_{28}=0.0 \pm 0.1\right)$; flux from malate to oxaloacetate $\left(\mathrm{v}_{30 \mathrm{f}}=0.00 \pm 0.01\right)$; net and 
exchange fluxes between glycine and $\mathrm{CO}_{2}+5,10$-methylene-THF $\left(\mathrm{v}_{55 \mathrm{f}}=0.0 \pm 0.3 ; \mathrm{v}_{55 \mathrm{~b}}=0.0 \pm 0.1\right)$; flux from glycine and acetaldehyde to threonine $\left(\mathrm{v}_{56 \mathrm{~b}}=0.08 \pm 0.03\right)$; and fluxes from aspartate and threonine to isoleucine $\left(\mathrm{v}_{64}, \mathrm{v}_{65}=0.00 \pm 0.01\right)$. All of these reactions were then removed from the model. The resulting minimal model consisted of 81 reactions (Appendix A).

${ }^{13} \mathrm{C}-\mathrm{MFA}$ performed with this minimal model produced statistically acceptable fits for all data sets, including combined flux analysis (Table 2). The minimized SSR values for the minimal model were similar to the SSR values obtained with the extended model (Table 1), thus confirming that the excluded reactions were not necessary to reproduce the measured mass isotopomer distributions. The estimated metabolic fluxes for $C$. acetobutylicum determined with the minimal model are shown schematically in Figure 1. The complete flux results are given in Supplementary Materials.

\subsection{An active pathway from pyruvate to fumarate via aspartate}

As described above, three fluxes in the TCA cycle were shown to carry no significant flux. In particular, the experiment with $\left[1-{ }^{13} \mathrm{C}\right]$ glucose provided strong evidence that there was no flux from malate to oxaloacetate. As shown in Figure $2,\left[1-{ }^{13} \mathrm{C}\right]$ glucose was first converted to $\left[3-{ }^{13} \mathrm{C}\right]$ pyruvate through glycolysis and then to $\left[3-{ }^{13} \mathrm{C}\right]$ aspartate. Given that fumarate is a rotationally symmetric molecule, $\left[3-{ }^{13} \mathrm{C}\right]$ aspartate then produced $50 \%\left[3-{ }^{13} \mathrm{C}\right]$ fumarate and $50 \%\left[2-{ }^{13} \mathrm{C}\right]$ fumarate. The fact that we did not observe any labeling in the first two carbon atoms of aspartate, i.e. $\mathrm{m} / \mathrm{z} 302$ fragment of aspartate was unlabeled (Figure 2), clearly indicated that fumarate and malate were not converted to oxaloacetate.

The net result of this incomplete TCA cycle was the formation of the following pathway from pyruvate to fumarate in $C$. acetobutylicum: pyruvate $\rightarrow$ oxaloacetate $\rightarrow$ aspartate $\rightarrow$ fumarate (Figure 
2 and 3A). The driving force for this pathway is the growth-associated conversion of aspartate to fumarate as part of the biosynthesis of arginine and histidine. Our flux results suggested that fumarate was converted to malate, which could potentially be recycled back to pyruvate via malic enzyme. To provide additional support for this result, we performed follow-up labeling experiments with [4-

$\left.{ }^{13} \mathrm{C}\right]$ aspartate and $\left[\mathrm{U}_{-}{ }^{13} \mathrm{C}\right]$ fumarate. Figure 3 shows the measured ${ }^{13} \mathrm{C}$-labeling of intracellular aspartate, glutamate, fumarate, malate and alanine. $\left[4{ }^{13} \mathrm{C}\right]$ Aspartate labeled intracellular glutamate $(92 \% \mathrm{M}+1)$, fumarate $(86 \% \mathrm{M}+1)$, and malate $(67 \% \mathrm{M}+1)$. These data support the notion that carbon flows from aspartate to fumarate and then to malate. $\left[\mathrm{U}-{ }^{13} \mathrm{C}\right]$ Fumarate on the other hand only labeled intracellular malate (58\% M+4), which also confirms that fumarate was converted to malate but malate was not converted to oxaloacetate.

\subsection{Succinate and succinyl-CoA are disconnected from TCA cycle}

Our flux analysis results revealed that there was no measurable flux between $\alpha$-ketoglutarate and succinyl-CoA, and between succinate and fumarate. The net effect of the absence of these fluxes is that succinate and succinyl-CoA effectively become disconnected from the TCA cycle. During cell growth, however, succinyl-CoA is converted to succinate as part of biosynthesis of lysine and methionine. If succinate is not recycled back to succinyl-CoA, succinate will become a dead-end product in the model. In fact, Amador-Noguez et al. (2010) did observe some succinate accumulation in the medium. However, inspection of their data reveals that succinate excretion rate was about 1000-fold smaller than excretion rates of other products, thus suggesting that succinate must be largely recycled back to succinyl-CoA via a CoA transferase, as was also initially suggested by Senger and Papoutsakis (2008). Although several CoA transferase genes have been identified in the genome of C. acetobutylicum, it is still unclear which CoA transferase is responsible for this activity. 
Unfortunately, our flux analysis results did not provide a clear answer to the question: how are succinate or succinyl-CoA produced in the first place? Amador-Noguez et al. (2010) demonstrated

experimentally that ${ }^{13} \mathrm{C}$-aspartate and ${ }^{13} \mathrm{C}$-glutamate could both produce ${ }^{13} \mathrm{C}$-labeled succinate. The conversion of $\alpha$-ketoglutarate to succinyl-CoA can be catalyzed by 2-oxoglutarate synthase (1.2.7.3, CAC2458 and CAC2459) (Crown et al., 2011), which would explain the conversion of ${ }^{13} \mathrm{C}$-glutamate to succinate. Senger and Papoutsakis (2008) also proposed that fumarate could be converted to succinate during nucleotide biosynthesis via L-aspartate oxidase (1.4.3.16, CAC1024), which would explain the conversion of ${ }^{13} \mathrm{C}$-aspartate to succinate. In our minimal network model neither of these reactions were required, thus suggesting that both of these fluxes are negligible in the overall carbon metabolism of $C$. acetobutylicum, i.e. the minimal model without these reactions still produced a statistically acceptable fit of all ${ }^{13} \mathrm{C}$-labeling data with 292 redundant measurements. Taken together, these results clearly demonstrate the power of parallel labeling experiments, ${ }^{13} \mathrm{C}-\mathrm{MFA}$, and statistical analysis in identifying significant and insignificant metabolic fluxes in the context of the overall metabolism.

\subsection{Isoleucine is exclusively produced via citramalate synthase}

The flux results also suggested that isoleucine was not produced from aspartate or from threonine (Figure 4), but instead that isoleucine was produced exclusively from pyruvate and acetyl-CoA via citramalate synthase. Until now, no citramalate synthase gene has been reported for $C$.

acetobutylicum. To identify a putative citramalate synthase gene we performed BLASTp analysis. Several known citramalate synthases showed high homology with the CAC3174 gene, which is currently annotated as an $\alpha$-isopropylmalate synthase. BLASTp of CAC3174 against the protein database also pulled up several known citramalate synthases as top hits. These results suggested that CAC3174 could code for the citramalate synthase activity that was identified here by ${ }^{13} \mathrm{C}-\mathrm{MFA}$. 
CAC3174 is the first gene of the operon CAC3174-3173-3172-3171-3170-3169. The other five genes in this operon code for enzymes that catalyze sequential reactions in the proposed isoleucine biosynthesis pathway shown in Figure 4. Taken together, these results provide strong evidence that CAC3174 codes for citramalate synthase, which is the first reaction of the proposed isoleucine biosynthesis pathway in $C$. acetobutylicum.

\subsection{One-carbon metabolism}

Finally, our flux analysis results provided valuable insights into one-carbon metabolism in $C$. acetobutylicum. As shown in Figure 5A, $\mathrm{C}_{1}$ units (which are needed for biosynthesis of methionine, purines and thymidine) were almost exclusively synthesized from pyruvate via pyruvate formate lyase and formate-tetrahydrofolate ligase. The conversion of serine to glycine did not contribute significantly to $\mathrm{C}_{1}$ production. As discussed already in section 3.4 , there was also no significant flux from glycine to $\mathrm{CO}_{2}+5,10$-methylene-THF. Thus, we determined that almost all of the $\mathrm{C}_{1}$ units are derived from pyruvate in $C$. acetobutylicum. To further validate fluxes in this part of metabolism, we performed a follow-up labeling experiment with $\left[1-{ }^{13} \mathrm{C}\right]$ serine. $\left[1-{ }^{13} \mathrm{C}\right]$ Serine labeled glycine $(58 \%$ $\mathrm{M}+1)$, alanine $(11 \% \mathrm{M}+1)$ and aspartate $(8 \% \mathrm{M}+1)$ (Figure 5B), thus supporting the notion that carbon flows from serine to glycine and from serine to alanine via the conversion of serine to pyruvate.

\subsection{Revised model of C. acetobutylicum metabolism}

This work has provided several new insights into the metabolism of C. acetobutylicum that can have consequences for further efforts aimed at metabolic engineering of this organism for biofuels production, e.g. by engineering of redox and energy metabolism (Papoutsakis, 2008; Wang et al., 2013). As was described before (Crown et al., 2011), C. acetobutylicum catabolizes glucose 
exclusively through glycolysis. Neither the oxidative pentose phosphate pathway, nor the EntnerDoudoroff pathway are active in C. acetobutylicum. The vast majority (about 90\%) of pyruvate formed via glycolysis is converted to acetic and butyric acid during the growth phase. In this study, we established for the first time quantitatively using ${ }^{13} \mathrm{C}-\mathrm{MFA}$ that the oxidative and reductive branches of the TCA cycle are effectively unconnected. The oxidative branch of the TCA cycle is used exclusively to produce $\alpha$-ketoglutarate, which serves as the precursor for several amino acids. The reductive branch of the TCA cycle does not operate as was previously proposed. We determined that the net carbon flow is from pyruvate to aspartate to fumarate, which is then further converted to malate (Figure 3). Previously, Amador-Noguez et al. (2011) noted that during growth on ${ }^{13} \mathrm{C}$-glucose, ${ }^{13} \mathrm{C}$-labeled malate and fumarate were produced; however, during the stationary phase the same tracer did not label either of these metabolites. This previous unexpected observation can now be easily explained by the presence of the growth-associated pyruvate-to-fumarate pathway that was elucidated in this study.

\section{CONCLUSIONS}

This study clearly demonstrates the power of parallel labeling experiments, combined with ${ }^{13} \mathrm{C}-\mathrm{MFA}$ and statistical analysis, to elucidate and quantitatively validate metabolic network models (Ahn and Antoniewicz, 2013; Crown and Antoniewicz, 2013a). Here, four isotopic labeling experiments were successfully integrated for ${ }^{13} \mathrm{C}-\mathrm{MFA}$. For the first time, we provide quantitative metabolic fluxes for C. acetobutylicum with narrow confidence intervals. Since combined analysis of parallel labeling experiments can provide a large number of redundant measurements (here, 292 redundant measurements), it can serve as a valuable tool for validating metabolic network models. Although our initial metabolic model did not produce statistically acceptable fits, we were able to resolve all inconsistencies using a step-by-step process by inspecting residuals and proposing and testing 
updated network models. The final extended model was then trimmed to a minimal model that could still produce an acceptable fit of all data. We believe that this systematic procedure is a powerful and unbiased approach to network model validation and flux analysis.

Taken together, this study has provided new and important insights into the metabolism of $C$. acetobutylicum and has resolved a number of inconsistencies in previous models. The fluxes in the TCA cycle were resolved for the first time with high precision. Furthermore, we validated the structure of amino acid biosynthesis pathways. In particular, we identified that C. acetobutylicum produces isoleucine exclusively via citramalate synthase, which is likely encoded by the CAC3174 gene. In future work, we plan to focus on further elucidating the regulation of the pyruvate-tofumarate pathway using new analytical techniques, recently developed in our lab, based on tandem mass spectrometry (Antoniewicz, 2013c; Choi and Antoniewicz, 2011), which can allow complete resolution of aspartate labeling (Choi et al., 2012), and using new dynamic metabolic flux analysis approaches (Antoniewicz, 2013b; Leighty and Antoniewicz, 2011).

\section{ACKNOWLEDGEMENTS}

The work was supported by the genomic science grant from Department of Energy DE-SC0007092. The authors declare that they have no competing interests.

\section{REFERENCES}

Ahn, W. S., Antoniewicz, M. R., 2011. Metabolic flux analysis of CHO cells at growth and nongrowth phases using isotopic tracers and mass spectrometry. Metab Eng. 13, 598-609.

Ahn, W. S., Antoniewicz, M. R., 2013. Parallel labeling experiments with [1,2-13C]glucose and [U13C]glutamine provide new insights into CHO cell metabolism. Metab Eng. 15, 34-47. 
Amador-Noguez, D., Brasg, I. A., Feng, X. J., Roquet, N., Rabinowitz, J. D., 2011. Metabolome remodeling during the acidogenic-solventogenic transition in Clostridium acetobutylicum. Appl Environ Microbiol. 77, 7984-97.

Amador-Noguez, D., Feng, X. J., Fan, J., Roquet, N., Rabitz, H., Rabinowitz, J. D., 2010. Systemslevel metabolic flux profiling elucidates a complete, bifurcated tricarboxylic acid cycle in Clostridium acetobutylicum. J Bacteriol. 192, 4452-61.

Antoniewicz, M. R., 2013a. 13C metabolic flux analysis: optimal design of isotopic labeling experiments. Curr Opin Biotechnol. 24, 1116-21.

Antoniewicz, M. R., 2013b. Dynamic metabolic flux analysis--tools for probing transient states of metabolic networks. Curr Opin Biotechnol. 24, 973-8.

Antoniewicz, M. R., 2013c. Tandem mass spectrometry for measuring stable-isotope labeling. Curr Opin Biotechnol. 24, 48-53.

Antoniewicz, M. R., 2013d. Using Multiple Tracers for 13C Metabolic Flux Analysis. Methods Mol Biol. 985, 353-365.

Antoniewicz, M. R., Kelleher, J. K., Stephanopoulos, G., 2006. Determination of confidence intervals of metabolic fluxes estimated from stable isotope measurements. Metab Eng. 8, 324-37.

Antoniewicz, M. R., Kelleher, J. K., Stephanopoulos, G., 2007a. Accurate assessment of amino acid mass isotopomer distributions for metabolic flux analysis. Anal Chem. 79, 7554-9.

Antoniewicz, M. R., Kelleher, J. K., Stephanopoulos, G., 2007b. Elementary metabolite units (EMU): a novel framework for modeling isotopic distributions. Metab Eng. 9, 68-86.

Antoniewicz, M. R., Kelleher, J. K., Stephanopoulos, G., 2011. Measuring deuterium enrichment of glucose hydrogen atoms by gas chromatography/mass spectrometry. Anal Chem. 83, 3211-6.

Antoniewicz, M. R., Kraynie, D. F., Laffend, L. A., Gonzalez-Lergier, J., Kelleher, J. K., Stephanopoulos, G., 2007c. Metabolic flux analysis in a nonstationary system: fed-batch 
fermentation of a high yielding strain of E. coli producing 1,3-propanediol. Metab Eng. 9, $277-92$.

Caspi, R., Altman, T., Dreher, K., Fulcher, C. A., Subhraveti, P., Keseler, I. M., Kothari, A., Krummenacker, M., Latendresse, M., Mueller, L. A., Ong, Q., Paley, S., Pujar, A., Shearer, A. G., Travers, M., Weerasinghe, D., Zhang, P., Karp, P. D., 2012. The MetaCyc database of metabolic pathways and enzymes and the BioCyc collection of pathway/genome databases. Nucleic Acids Res. 40, D742-53.

Choi, J., Antoniewicz, M. R., 2011. Tandem mass spectrometry: a novel approach for metabolic flux analysis. Metab Eng. 13, 225-33.

Choi, J., Grossbach, M. T., Antoniewicz, M. R., 2012. Measuring complete isotopomer distribution of aspartate using gas chromatography/tandem mass spectrometry. Anal Chem. 84, 4628-32.

Crown, S. B., Antoniewicz, M. R., 2013a. Parallel labeling experiments and metabolic flux analysis: past, present and future methodologies. Metab Eng. 16, 21-32.

Crown, S. B., Antoniewicz, M. R., 2013b. Publishing 13C metabolic flux analysis studies: A review and future perspectives. Metab Eng. 20, 42-48.

Crown, S. B., Indurthi, D. C., Ahn, W. S., Choi, J., Papoutsakis, E. T., Antoniewicz, M. R., 2011. Resolving the TCA cycle and pentose-phosphate pathway of Clostridium acetobutylicum ATCC 824: Isotopomer analysis, in vitro activities and expression analysis. Biotechnol J. 6, $300-5$.

Durre, P., 1998. New insights and novel developments in clostridial acetone/butanol/isopropanol fermentation. Appl Microbiol Biotechnol. 49, 639-648.

Fernandez, C. A., Des Rosiers, C., Previs, S. F., David, F., Brunengraber, H., 1996. Correction of 13C mass isotopomer distributions for natural stable isotope abundance. J Mass Spectrom. 31, $255-62$. 
Furdui, C., Ragsdale, S. W., 2000. The role of pyruvate ferredoxin oxidoreductase in pyruvate synthesis during autotrophic growth by the Wood-Ljungdahl pathway. J Biol Chem. 275, 28494-9.

Kanehisa, M., Goto, S., 2000. KEGG: kyoto encyclopedia of genes and genomes. Nucleic Acids Res. $28,27-30$.

Kanehisa, M., Goto, S., Sato, Y., Furumichi, M., Tanabe, M., 2012. KEGG for integration and interpretation of large-scale molecular data sets. Nucleic Acids Res. 40, D109-14.

Lee, J., Yun, H., Feist, A. M., Palsson, B. O., Lee, S. Y., 2008. Genome-scale reconstruction and in silico analysis of the Clostridium acetobutylicum ATCC 824 metabolic network. Appl Microbiol Biotechnol. 80, 849-62.

Leighty, R. W., Antoniewicz, M. R., 2011. Dynamic metabolic flux analysis (DMFA): a framework for determining fluxes at metabolic non-steady state. Metab Eng. 13, 745-55.

Leighty, R. W., Antoniewicz, M. R., 2012. Parallel labeling experiments with [U-(13)C]glucose validate E. coli metabolic network model for (13)C metabolic flux analysis. Metab Eng. 14, $533-541$.

Leighty, R. W., Antoniewicz, M. R., 2013. COMPLETE-MFA: Complementary parallel labeling experiments technique for metabolic flux analysis. Metab Eng. 20, 49-55.

Nolling, J., Breton, G., Omelchenko, M. V., Makarova, K. S., Zeng, Q., Gibson, R., Lee, H. M., Dubois, J., Qiu, D., Hitti, J., Wolf, Y. I., Tatusov, R. L., Sabathe, F., Doucette-Stamm, L., Soucaille, P., Daly, M. J., Bennett, G. N., Koonin, E. V., Smith, D. R., 2001. Genome sequence and comparative analysis of the solvent-producing bacterium Clostridium acetobutylicum. J Bacteriol. 183, 4823-38.

Papoutsakis, E. T., 1984. Equations and calculations for fermentations of butyric acid bacteria. Biotechnol Bioeng. 26, 174-87. 
Papoutsakis, E. T., 2008. Engineering solventogenic clostridia. Curr Opin Biotechnol. 19, 420-9.

Paredes, C. J., Alsaker, K. V., Papoutsakis, E. T., 2005. A comparative genomic view of clostridial sporulation and physiology. Nat Rev Microbiol. 3, 969-78.

Senger, R. S., Papoutsakis, E. T., 2008. Genome-scale model for Clostridium acetobutylicum: Part I. Metabolic network resolution and analysis. Biotechnol Bioeng. 101, 1036-52.

Stephanopoulos, G., 2007. Challenges in engineering microbes for biofuels production. Science. 315, $801-4$.

Stephanopoulos, G., 2008. Metabolic engineering: enabling technology for biofuels production. Metab Eng. 10, 293-4.

Swarup, A., Lu, J., DeWoody, K. C., Antoniewicz, M. R., 2014. Metabolic network reconstruction, growth characterization and (13)C-metabolic flux analysis of the extremophile Thermus thermophilus HB8. Metab Eng. 24, 173-80.

Tang, J. K., You, L., Blankenship, R. E., Tang, Y. J., 2012. Recent advances in mapping environmental microbial metabolisms through $13 \mathrm{C}$ isotopic fingerprints. Journal of the Royal Society, Interface / the Royal Society. 9, 2767-80.

Tang, Y. J., Sapra, R., Joyner, D., Hazen, T. C., Myers, S., Reichmuth, D., Blanch, H., Keasling, J. D., 2009. Analysis of metabolic pathways and fluxes in a newly discovered thermophilic and ethanol-tolerant Geobacillus strain. Biotechnol Bioeng. 102, 1377-86.

Tomas, C. A., Welker, N. E., Papoutsakis, E. T., 2003. Overexpression of groESL in Clostridium acetobutylicum results in increased solvent production and tolerance, prolonged metabolism, and changes in the cell's transcriptional program. Appl Environ Microbiol. 69, 4951-65.

Tracy, B. P., Jones, S. W., Fast, A. G., Indurthi, D. C., Papoutsakis, E. T., 2012. Clostridia: the importance of their exceptional substrate and metabolite diversity for biofuel and biorefinery applications. Curr Opin Biotechnol. 23, 364-81. 
Wang, Q., Venkataramanan, K. P., Huang, H., Papoutsakis, E. T., Wu, C. H., 2013. Transcription factors and genetic circuits orchestrating the complex, multilayered response of Clostridium acetobutylicum to butanol and butyrate stress. BMC Syst Biol. 7, 120.

Wu, B., Zhang, B., Feng, X., Rubens, J. R., Huang, R., Hicks, L. M., Pakrasi, H. B., Tang, Y. J., 2010. Alternative isoleucine synthesis pathway in cyanobacterial species. Microbiology. 156, 596-602.

Yoo, H., Antoniewicz, M. R., Stephanopoulos, G., Kelleher, J. K., 2008. Quantifying reductive carboxylation flux of glutamine to lipid in a brown adipocyte cell line. J Biol Chem. 283, 20621-7.

Young, J. D., Walther, J. L., Antoniewicz, M. R., Yoo, H., Stephanopoulos, G., 2008. An elementary metabolite unit (EMU) based method of isotopically nonstationary flux analysis. Biotechnol Bioeng. 99, 686-99. 


\section{FIGURE LEGENDS}

Figure 1. Metabolic flux map of central carbon metabolism for C. acetobutylicum grown anaerobically in batch culture with glucose as the main carbon substrate (estimated flux \pm stdev). Fluxes were estimated using ${ }^{13} \mathrm{C}$-MFA with the minimal network model for $C$. acetobutylicum (see section 3.4) by simultaneously fitting all four labeling data sets (i.e. from [U- $\left.{ }^{13} \mathrm{C}\right] \mathrm{glucose}$ and $[1-$ $\left.{ }^{13} \mathrm{C}\right]$ glucose tracer experiments) to a single flux model. Fluxes shown with dotted lines were determined to carry no flux in the extended model and were therefore not present in the minimal model.

Figure 2. Pyruvate to fumarate pathway in C. acetobutylicum elucidated with isotopic tracer experiments and ${ }^{13} \mathrm{C}$-MFA. Experiments with $\left[1-{ }^{13} \mathrm{C}\right]$ glucose provided evidence that malate was not converted to oxaloacetate, since aspartate was not labeled at the first two carbon positions $(\mathrm{m} / \mathrm{z} 302$ fragment, C1-C2), but was labeled at the last two carbon positions ( $\mathrm{m} / \mathrm{z} 418$ fragment, C1-C4).

Figure 3. (A) Aspartate metabolism in C. acetobutylicum (highlighted with blue arrows) revealed by isotopic tracer experiments. (B) Relative abundances of M+1 mass isotopomer in intracellular metabolites from labeling experiment with $\left[4-{ }^{13} \mathrm{C}\right]$ aspartate as tracer. (C) Mass isotopomer

distributions of intracellular metabolites from labeling experiment with $\left[\mathrm{U}_{-}{ }^{13} \mathrm{C}\right]$ fumarate as tracer.

Figure 4. Putative citramalate synthase in C. acetobutylicum ATCC 824. Citramalate synthase (EC 2.3.1.182) is putatively coded by CAC3174, which is part of the operon CAC3174-3173-3172-31713170-3169. The other five genes in this operon code for enzymes that catalyze sequential reactions in the proposed isoleucine biosynthesis pathway. 
Figure 5. (A) Metabolic flux map of one-carbon metabolism and isoleucine biosynthesis in $C$. acetobutylicum (estimated flux \pm stdev). Fluxes were estimated using ${ }^{13} \mathrm{C}-\mathrm{MFA}$ and the minimal network model. Fluxes shown with dotted lines were determined to carry no flux in the extended model and were therefore not present in the minimal model. (B) Relative abundances of M+1 mass isotopomer in intracellular metabolites from labeling experiment with $\left[1-{ }^{13} \mathrm{C}\right]$ serine as tracer. 


\section{TABLES}

\section{Table 1. Goodness-of-fit analysis for different metabolic network models of $C$. acetobutylicum}

\begin{tabular}{|c|c|c|c|c|c|c|c|}
\hline \multirow{2}{*}{ No. of fitted data sets } & & \multicolumn{2}{|c|}{$[\mathrm{U}]$ Gluc } & \multicolumn{2}{|c|}{ [1]Gluc } & \multicolumn{2}{|c|}{ [U]Gluc \& [1]Gluc } \\
\hline & & \multicolumn{2}{|r|}{2} & \multicolumn{2}{|r|}{2} & \multicolumn{2}{|r|}{4} \\
\hline \multicolumn{2}{|c|}{ No. of fitted labeling measurements* } & \multicolumn{2}{|r|}{202} & \multicolumn{2}{|r|}{138} & \multicolumn{2}{|c|}{340} \\
\hline \multicolumn{2}{|c|}{ No. of redundant measurements $* *$} & \multicolumn{2}{|r|}{178} & \multicolumn{2}{|r|}{114} & \multicolumn{2}{|c|}{292} \\
\hline \multicolumn{2}{|c|}{ Acceptable SSR values (95\% Conf.)** } & \multicolumn{2}{|c|}{$[143,217]$} & \multicolumn{2}{|c|}{$[86,145]$} & \multicolumn{2}{|c|}{$[246,341]$} \\
\hline Network model*** & $\begin{array}{l}\text { No. of } \\
\text { reactions }\end{array}$ & SSR & Accepted & SSR & Accepted & SSR & Accepted \\
\hline Base & 86 & 3706 & No & 489 & No & 6789 & No \\
\hline Base + Ac & 87 & 917 & No & 355 & No & 4342 & No \\
\hline Base + Ac + Ile & 89 & 419 & No & 103 & Yes & 3373 & No \\
\hline Base + Ac + Ile + PFOR & 90 & 220 & No & 98 & Yes & 672 & No \\
\hline $\mathrm{Base}+\mathrm{Ac}+\mathrm{Ile}+\mathrm{PFOR}+\mathrm{CO}_{2}$ & 91 & 201 & Yes & 92 & Yes & 312 & Yes \\
\hline Minimal model & 81 & 208 & Yes & 92 & Yes & 320 & Yes \\
\hline
\end{tabular}

* Number of fitted measurements includes only mass isotopomers that were non-zero after correction for natural isotope abundances.

** Number of redundant measurements and acceptable range of SSR values for the minimal model.

*** The following reactions were subsequently added to the base model: $+\mathrm{Ac}=$ dilution of intracellular AcCoA by external acetate $\left(\mathrm{v}_{91}\right) ;+$ Ile $=$ two alternative isoleucine biosynthesis pathways $\left(\mathrm{v}_{64}\right.$ and $\left.\mathrm{v}_{66}\right) ;+\mathrm{PFOR}=$ reversible PFOR reaction $\left(\mathrm{v}_{21}\right) ;+\mathrm{CO} 2=$ dilution of intracellular $\mathrm{CO}_{2}$ by unlabeled $\mathrm{CO}_{2}$ sources $\left(\mathrm{v}_{90}\right)$. 
Table 2. Fitting of single and multiple labeling experiments with ${ }^{13} \mathrm{C}-\mathrm{MFA} *$

\begin{tabular}{|c|c|c|c|c|c|c|}
\hline $\begin{array}{l}\text { [U]Gluc } \\
\text { Repl. } 1\end{array}$ & $\begin{array}{l}\text { [U]Gluc } \\
\text { Repl. } 2\end{array}$ & $\begin{array}{l}\text { [1]Gluc } \\
\text { Repl. } 1\end{array}$ & $\begin{array}{l}\text { [1]Gluc } \\
\text { Repl. } 2\end{array}$ & $\begin{array}{c}\text { No. of fitted labeling } \\
\text { measurements } * *\end{array}$ & $\begin{array}{l}\text { No. of redundant } \\
\text { measurements }\end{array}$ & SSR \\
\hline \multirow[t]{4}{*}{$X$} & & & & 101 & 89 & 108 \\
\hline & $X$ & & & 101 & 89 & 85 \\
\hline & & $X$ & & 69 & 57 & 47 \\
\hline & & & $X$ & 69 & 57 & 43 \\
\hline \multirow[t]{2}{*}{$X$} & $\mathrm{X}$ & & & 202 & 178 & 208 \\
\hline & & $X$ & $X$ & 138 & 114 & 92 \\
\hline$X$ & $X$ & $X$ & $X$ & 340 & 292 & 320 \\
\hline
\end{tabular}

* Minimal model was used for ${ }^{13} \mathrm{C}-\mathrm{MFA}$

** Number of fitted measurements includes only mass isotopomers that were non-zero after correction for natural isotope abundances. 
Appendix A. Metabolic network models of Clostridium acetobutylicum used for ${ }^{13} \mathrm{C}$ metabolic flux analysis.

B = base model (initial model, constructed based on KEGG and BioCyc databases and two published genome-scale models)

$\mathbf{E}=$ extended model (model with additional reactions that were found to improve the fits of ${ }^{13} \mathrm{C}$ labeling data)

$\mathbf{M}=$ minimal model (smallest model that could still produce an acceptable fit of all ${ }^{13} \mathrm{C}$-labeling data in this study)

\section{Glycolysis}

$\left[\right.$ B E M ] $\mathrm{v}_{1}$ Gluc.ext (abcdef) + ATP $\rightarrow$ G6P (abcdef) + ADP

[ B E M ] $v_{2}$ G6P (abcdef) $\leftrightarrow$ F6P (abcdef)

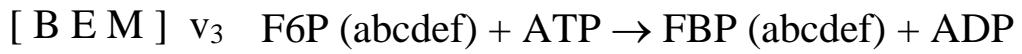

$[\mathrm{B} \mathrm{E} \mathrm{M}] \mathrm{v}_{4} \quad \mathrm{FBP}($ abcdef $) \leftrightarrow$ DHAP (cba) + GAP (def)

[ B E M ] $v_{5} \quad$ DHAP $(a b c) \leftrightarrow$ GAP $(a b c)$

$\left[\mathrm{B} \mathrm{E} \mathrm{M} \mathrm{]} \mathrm{v}_{6} \mathrm{GAP}(\mathrm{abc})+\mathrm{ADP}+\mathrm{NAD} \leftrightarrow 3 \mathrm{PG}(\mathrm{abc})+\mathrm{ATP}+\mathrm{NADH}\right.$

$[\mathrm{B} \mathrm{EM}] \mathrm{v}_{7} \quad 3 \mathrm{PG}(\mathrm{abc}) \leftrightarrow \operatorname{PEP}(\mathrm{abc})$

$[\mathrm{B} \mathrm{EM}] \mathrm{v}_{8} \mathrm{PEP}(\mathrm{abc})+\mathrm{ADP} \rightarrow \mathrm{Pyr}(\mathrm{abc})+\mathrm{ATP}$

\section{Pentose Phosphate Pathway}

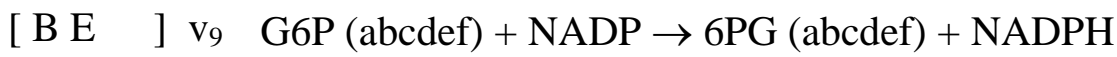




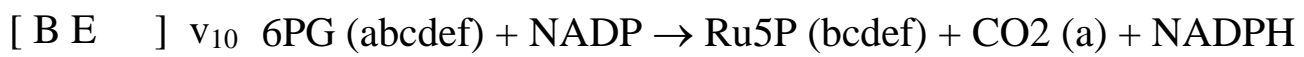

[ B E M ] $v_{11}$ Ru5P (abcde) $\leftrightarrow$ X5P (abcde)

[ B E M ] v 12 Ru5P (abcde) $\leftrightarrow$ R5P (abcde)

[ B E M ] $\mathrm{v}_{13}$ X5P (abcde) $\leftrightarrow$ TK-C2 (ab) + GAP (cde)

[ B E M ] v v $_{14}$ F6P (abcdef) $\leftrightarrow$ TK-C2 (ab) + E4P (cdef)

[ B E M ] V 15 S7P (abcdefg) $\leftrightarrow$ TK-C2 (ab) + R5P (cdefg)

[ B E M ] v $_{16}$ F6P (abcdef) $\leftrightarrow$ TA-C3 (abc) + GAP (def)

[ B E M ] $v_{17}$ S7P (abcdefg) $\leftrightarrow$ TA-C3 (abc) + E4P (defg)

\section{Entner-Doudoroff Pathway}

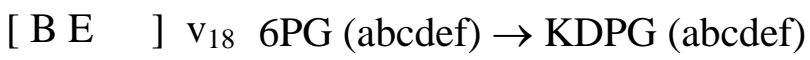

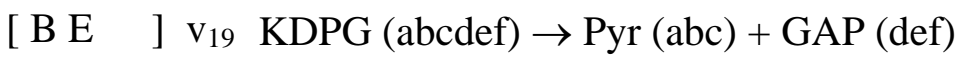

\section{Pyruvate Metabolism}

$\left[\right.$ B E M ] $v_{20} \operatorname{Pyr}(\mathrm{abc}) \rightarrow \operatorname{AcCoA}(\mathrm{bc})+$ Form (a)

$[\quad \mathrm{E} \mathrm{M}]^{*} \mathrm{v}_{21} \operatorname{Pyr}(\mathrm{abc}) \leftrightarrow \mathrm{PFOR}-\mathrm{C} 2(\mathrm{bc})+\mathrm{CO} 2(\mathrm{a})$

$\left[\mathrm{B} E \mathrm{E}\right.$ ] $\mathrm{v}_{22}$ PFOR-C2 $(\mathrm{ab})+2 \mathrm{oxFd} \rightarrow \mathrm{AcCoA}(\mathrm{ab})+2 \mathrm{redFd}$

\section{TCA Cycle}

$\left[\right.$ B E M ] v $v_{23}$ OAC (abcd) + AcCoA (ef) $\rightarrow$ Cit (efbcda)

[ B E M ] $\mathrm{v}_{24}$ Cit (abcdef) $\leftrightarrow$ ICit (abcdef)

[ B E M ] $v_{25}$ ICit (abcdef) $+\mathrm{NADP} \leftrightarrow \mathrm{AKG}($ abcde $)+\mathrm{CO} 2$ (f) $+\mathrm{NADPH}$ 
[ B E ] $\mathrm{v}_{26} \mathrm{AKG}($ abcde $)+2 \mathrm{oxFd} \rightarrow \mathrm{SucCoA}$ (bcde) $+\mathrm{CO} 2(\mathrm{a})+2 \mathrm{redFd}$

[ B E M ] $v_{27} \operatorname{SucCoA}($ abcd $)+$ ADP $\leftrightarrow$ Suc $(1 / 2$ abcd $+1 / 2$ dcba $)+$ ATP

[ B E ] $v_{28}$ Suc $(1 / 2$ abcd $+1 / 2$ dcba $)+N A D \rightarrow$ Fum $(1 / 2$ abcd $+1 / 2$ dcba $)+N A D H$

[ B E M ] $v_{29}$ Fum $(1 / 2$ abcd $+1 / 2$ dcba $) \leftrightarrow \operatorname{Mal}($ abcd $)$

[ B E ] $\mathrm{V}_{30} \mathrm{Mal}(\mathrm{abcd})+\mathrm{NAD} \leftrightarrow \mathrm{OAC}(\mathrm{abcd})+\mathrm{NADH}$

\section{Amphibolic Reactions}

[ B E M ] $v_{31} \mathrm{Mal}(\mathrm{abcd})+\mathrm{NADP} \rightarrow \operatorname{Pyr}(\mathrm{abc})+\mathrm{CO} 2(\mathrm{~d})+\mathrm{NADPH}$

$\left[\right.$ B E M ] $v_{32}$ Pyr $(a b c)+\mathrm{CO} 2(d)+\mathrm{ATP} \rightarrow \mathrm{OAC}(\mathrm{abcd})+\mathrm{ADP}$

\section{Acid and Solvent Formation}

$[\mathrm{B} E \mathrm{M}] \mathrm{v}_{33} \mathrm{AcCoA}(\mathrm{ab})+\mathrm{ADP} \rightarrow \mathrm{Ac}(\mathrm{ab})+\mathrm{ATP}$

$\left[\right.$ B E M ] $v_{34} \operatorname{Pyr}(a b c)+\operatorname{Pyr}($ def $) \rightarrow$ Acn (cbef) $+\mathrm{CO} 2(a)+\mathrm{CO} 2(d)$

[ B E M ] $v_{35} \operatorname{Pyr}(a b c) \rightarrow$ Acetal (bc) $+\mathrm{CO} 2(a)$

$\left[\right.$ B E M ] $v_{36}$ Acetal $(a b)+\mathrm{NADH} \leftrightarrow \mathrm{EtOH}(\mathrm{ab})+\mathrm{NAD}$

[ B E M ] $v_{37}$ AcCoA $(a b)+\mathrm{NADH} \rightarrow$ Acetal $(a b)+\mathrm{NAD}$

$[\mathrm{B} E \mathrm{M}] \mathrm{v}_{38} \mathrm{AcCoA}(\mathrm{ab})+\mathrm{AcCoA}(\mathrm{cd}) \leftrightarrow \mathrm{AcAcCoA}(\mathrm{abcd})$

$\left[\right.$ B E M ] $v_{39}$ AcAc (abcd) $\rightarrow$ Acne (bcd) $+\mathrm{CO} 2($ a)

$\left[\mathrm{B} \mathrm{E} \mathrm{M} \mathrm{]} \mathrm{V}_{40}\right.$ AcAcCoA (abcd) + NADPH + NADH $\rightarrow \mathrm{BtCoA}(\mathrm{abcd})+\mathrm{NADP}+\mathrm{NAD}$

$[\mathrm{BEE}] \mathrm{v}_{41} \mathrm{BtCoA}(\mathrm{abcd})+\mathrm{ADP} \rightarrow \mathrm{Bt}(\mathrm{abcd})+\mathrm{ATP}$

$\left[\mathrm{B} \mathrm{E} \mathrm{M} \mathrm{]} \mathrm{v}_{42} \mathrm{BtCoA}(\mathrm{abcd})+2 \mathrm{NADH} \rightarrow \mathrm{BtOH}(\mathrm{abcd})+2 \mathrm{NAD}\right.$

$\left[\mathrm{B} \mathrm{E} \mathrm{M} \mathrm{]} \mathrm{v}_{43} \mathrm{Bt}(\mathrm{abcd})+\mathrm{AcAcCoA}(\mathrm{efgh}) \rightarrow \mathrm{BtCoA}(\mathrm{abcd})+\mathrm{AcAc}(\right.$ efgh $)$ 
$[\mathrm{BEM}] \mathrm{v}_{44} \mathrm{Ac}(\mathrm{ab})+\mathrm{AcAcCoA}(\mathrm{cdef}) \rightarrow \operatorname{AcCoA}(\mathrm{ab})+\mathrm{AcAc}(\mathrm{cdef})$

\section{Amino Acid Biosynthesis}

[ B E M ] v $45_{5}$ AKG (abcde) + NADPH + NH3 $\leftrightarrow$ Glu (abcde) + NADP

[ B E M ] $\mathrm{v}_{46}$ Glu (abcde) $+\mathrm{ATP}+\mathrm{NH} 3 \leftrightarrow \mathrm{Gln}($ abcde $)+\mathrm{ADP}$

$\left[\right.$ B E M ] $v_{47}$ Glu (abcde) + ATP + $2 \mathrm{NADPH} \rightarrow$ Pro (abcde) + ADP + 2 NADP

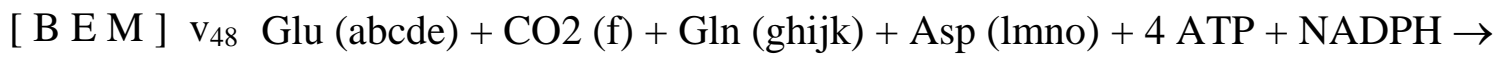
Arg (abcdef) + AKG (ghijk) + Fum (lmno) + 3 ADP + AMP + NADP

$\left[\right.$ B E M ] v v $_{49}$ OAC (abcd) + Glu (efghi) $\rightarrow$ Asp (abcd) + AKG (efghi)

[ B E M ] $v_{50}$ Asp (abcd) + Gln (efghi) + ATP $\leftrightarrow$ Asn (abcd) + Glu (efghi) + AMP

[ B E M ] v $_{51}$ Pyr $(a b c)+$ Glu $($ defgh $) \leftrightarrow$ Ala $(a b c)+$ AKG (defgh)

[ B E M ] v $_{52} 3 \mathrm{PG}(\mathrm{abc})+\mathrm{Glu}(\mathrm{defgh})+\mathrm{NAD} \rightarrow \mathrm{Ser}(\mathrm{abc})+\mathrm{AKG}(\mathrm{defgh})+\mathrm{NADH}$

[ B E M ] $v_{53} \operatorname{Pyr}(a b c)+N H 3 \leftrightarrow \operatorname{Ser}(a b c)$

[ B E M ] $v_{54} \operatorname{Ser}(a b c) \leftrightarrow$ Gly (ab) + MEETHF (c)

[ B E ] v v5 Gly (ab) + NAD $\leftrightarrow \mathrm{CO} 2(a)+\operatorname{MEETHF}(b)+\mathrm{NADH}+\mathrm{NH} 3$

$[\mathrm{B} \mathrm{EM}]^{*} \mathrm{v}_{56} \operatorname{Thr}(\mathrm{abcd}) \rightarrow$ Gly $(\mathrm{ab})+$ Acetal $(\mathrm{cd})$

[ B E M ] v $_{57} \mathrm{Ser}(\mathrm{abc})+\mathrm{AcCoA}(\mathrm{de})+2 \mathrm{ATP}+3 \mathrm{NADPH}+\operatorname{redTRX}+\mathrm{SO} 4 \rightarrow \mathrm{Cys}(\mathrm{abc})+$ Ac (de) + ADP + AMP + 3 NADP + oxTRX

[ B E M ] v58 Asp (abcd) + Pyr (efg) + Glu (hijkl) + SucCoA (mnop) + ATP + 2 NADPH $\rightarrow$ LL-DAP $(1 / 2$ abcdgfe $+1 / 2$ efgdcba $)+$ AKG (hijkl) + Suc $(1 / 2$ mnop + 1/2 ponm $)+$ $\mathrm{ADP}+2 \mathrm{NADP}$

[ B E M ] V59 LL-DAP (1/2 abcdefg + 1/2 gfedcba) $\rightarrow$ Lys (abcdef $)+$ CO2 (g) 
$\left[\right.$ B E M ] $\mathrm{v}_{60}$ Asp (abcd) + 2 ATP + $2 \mathrm{NADPH} \rightarrow \mathrm{Thr}(\mathrm{abcd})+2 \mathrm{ADP}+2 \mathrm{NADP}$

[ B E M ] v $_{61}$ Asp (abcd) + METHF (e) + Cys (fgh) + SucCoA (ijkl) + ATP + $2 \mathrm{NADPH} \rightarrow$

Met $($ abcde $)+$ Pyr $($ fgh $)+$ Suc $(1 / 2 \mathrm{ijkl}+1 / 21 \mathrm{kji})+\mathrm{ADP}+2 \mathrm{NADP}+\mathrm{NH} 3$

[ B E M ] v $_{62}$ Pyr (abc) + Pyr (def) + Glu (ghijk) + NADPH $\rightarrow$ Val (abcef) + CO2 (d) + AKG (ghijk) + NADP

[ B E M ] v $_{63} \operatorname{AcCoA}(a b)+\operatorname{Pyr}(c d e)+\operatorname{Pyr}($ fgh $)+$ Glu (ijklm $)+\mathrm{NADPH}+\mathrm{NAD} \rightarrow \mathrm{Leu}$ (abdghe) $+\mathrm{CO} 2(\mathrm{c})+\mathrm{CO} 2(\mathrm{f})+\mathrm{AKG}(\mathrm{ijklm})+\mathrm{NADP}+\mathrm{NADH}$

[ $\quad \mathrm{E} \quad] \quad \mathrm{v}_{64} \mathrm{Thr}(\mathrm{abcd})+\mathrm{Pyr}(\mathrm{efg})+\mathrm{Glu}(\mathrm{hijkl})+\mathrm{NADPH} \rightarrow \mathrm{Ile}(\mathrm{abfcdg})+\mathrm{CO} 2(\mathrm{e})+$ AKG (hijkl) + NADP + NH3

[ B E ] $v_{65}$ Asp (abcd) + Pyr (efg) + Glu (hijkl) + SucCoA (mnop) + ATP + 3 NADPH $\rightarrow$ Ile (abfcdg) + CO2 (e) + AKG (hijkl) + Suc(mnop) + ADP + 3 NADP + NH3

[ $\quad$ E M ] v $_{66} \operatorname{Pyr}(\mathrm{abc})+\mathrm{Pyr}(\mathrm{def})+\mathrm{AcCoA}(\mathrm{gh})+\mathrm{Glu}(\mathrm{ijklm})+\mathrm{NAD}+\mathrm{NADPH} \rightarrow \mathrm{Ile}$ $($ ghbefc $)+\mathrm{CO} 2(\mathrm{a})+\mathrm{CO} 2(\mathrm{~d})+\mathrm{AKG}(\mathrm{ijklm})+\mathrm{NADH}+\mathrm{NADP}$

[ B E M ] v $67_{7}$ PEP (abc) + PEP (def) + E4P (ghij $)+$ Glu (klmno $)+$ ATP + NADPH $\rightarrow$ Phe (abcefghij) + CO2 (d) + AKG (klmno) + ADP + NADP

[ B E M ] v $68_{8} \mathrm{PEP}(\mathrm{abc})+\mathrm{PEP}(\mathrm{def})+\mathrm{E} 4 \mathrm{P}($ ghij $)+\mathrm{Glu}(\mathrm{klmno})+\mathrm{ATP}+\mathrm{NAD}+\mathrm{NADPH} \rightarrow$ Tyr (abcefghij) + CO2 (d) + AKG (klmno) + ADP + NADH + NADP

[ B E M ] v $_{69} \operatorname{Ser}(a b c)+$ R5P (defgh) + PEP (ijk) + E4P (lmno) + PEP (pqr) + Gln (stuvw) + 2 ATP + NADPH $\rightarrow$ Trp (abcedklmnoj) + CO2 (i) + GAP (fgh) + Pyr (pqr) + Glu (stuvw) + ADP + AMP + NADP

[ B E M ] v v0 R5P (abcde) + FTHF (f) + Gln (ghijk) + Asp (lmno) + 4 ATP + 2 NAD $\rightarrow$ His (edcbaf) + AKG (ghijk) + Fum (lmno) +3 ADP + AMP + 2 NADH 


\section{One-Carbon Metabolism}

$[$ B E M ] v71 MEETHF (a) + NADH $\rightarrow$ METHF (a) + NAD

[ B E M ] v72 MEETHF (a) + NADP $\leftrightarrow$ FTHF (a) + NADPH

$[$ B E M ] V73 Form (a) + ATP $\rightarrow$ FTHF (a) + ADP

\section{Redox Metabolism}

[ B E M ] $v_{74} 2 \mathrm{redFd}+\mathrm{NAD} \leftrightarrow 2 \mathrm{oxFd}+\mathrm{NADH}$

[ B E M ] $\mathrm{V}_{75} 2 \mathrm{redFd}+\mathrm{NADP} \leftrightarrow 2 \mathrm{oxFd}+\mathrm{NADPH}$

[ B E M ] $\mathrm{v}_{76} 2 \mathrm{redFd} \rightarrow 2 \mathrm{oxFd}+\mathrm{H} 2$

\section{Energy metabolism}

$[\mathrm{B} \mathrm{EM}]^{*} \mathrm{v}_{77} \mathrm{ATP} \rightarrow \mathrm{ADP}$

$\left[\mathrm{B} \mathrm{E} \mathrm{M} \mathrm{]} \mathrm{v}_{78} \mathrm{ATP}+\mathrm{AMP} \rightarrow 2 \mathrm{ADP}\right.$

\section{Transport}

[ B E M ] v79 $\mathrm{CO} 2$ (a) $\rightarrow \mathrm{CO} 2 . e x t(a)$

$[\mathrm{B} \mathrm{EM}] \mathrm{v}_{80} \mathrm{H} 2 \rightarrow \mathrm{H} 2 . \mathrm{ext}$

[ B E M ] v81 Ac (ab) $\rightarrow$ Ac.ext (ab)

$[$ B E M ] V82 Bt (abcd) $\rightarrow$ Bt.ext (abcd)

$[\mathrm{B} E \mathrm{M}] \mathrm{v}_{83}$ Acne $(\mathrm{abc}) \rightarrow$ Acne.ext $(\mathrm{abc})$

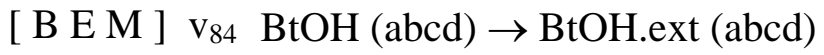


$[$ B E M ] v85 EtOH (ab) $\rightarrow$ EtOH.ext $(a b)$

[ B E M ] v86 Acn (abcd) $\rightarrow$ Acn.ext (abcd)

[ B E M ] v87 $_{8}$ NH3.ext $\rightarrow$ NH3

$[\mathrm{B} \mathrm{EM}] \mathrm{v}_{88} \quad \mathrm{SO} 4 . \mathrm{ext} \rightarrow \mathrm{SO} 4$

\section{Biomass Formation}

$$
\begin{aligned}
& {\left[\mathrm{B} \mathrm{E} \mathrm{M}{ }^{*} \mathrm{v}_{89}\right. \text { 0.410 Ala + 0.070 Arg + 0.082 Asn + 0.082 Asp + 0.643 Cys + 0.067 Glu + }} \\
& \text { 0.067 Gln + 0.570 Gly + 0.077 His + 0.230 Ile + 0.227 Leu + 0.188 Lys + 0.414 } \\
& \text { Met + 0.098 Phe + 0.241 Pro + 0.226 Ser + 0.217 Thr + 0.023 Trp + 0.423 Tyr } \\
& +0.619 \mathrm{Val}+0.267 \mathrm{G} 6 \mathrm{P}+0.225 \mathrm{~F} 6 \mathrm{P}+0.338 \mathrm{R} 5 \mathrm{P}+0.597 \mathrm{GAP}+0.2563 \mathrm{PG} \\
& +0.107 \mathrm{PEP}+0.335 \mathrm{Pyr}+1.813 \mathrm{AcCoA}+0.112 \mathrm{AKG}+0.284 \mathrm{OAC}+0.194 \\
& \text { MEETHF + 26.281 ATP + 0.763 NAD + 4.207 NADPH } \rightarrow \text { 37.28 Biomass + } \\
& \text { 26.281 ADP + 0.763 NADH + 4.207 NADP }
\end{aligned}
$$

\section{Dilution fluxes}

$[\quad \mathrm{EM}]^{*} \mathrm{v}_{90} \mathrm{CO} 2 \cdot$ unlabeled (a) $+\mathrm{CO} 2(\mathrm{~b}) \rightarrow \mathrm{CO} 2(\mathrm{a})+\mathrm{CO} 2 \cdot \operatorname{sink}(\mathrm{b})$

$[\mathrm{E} \mathrm{M}]^{*} \mathrm{v}_{91}$ Ac.unlabeled $(\mathrm{ab})+\mathrm{AcCoA}(\mathrm{cd}) \rightarrow \mathrm{AcCoA}(\mathrm{ab})+\mathrm{Ac} \cdot \operatorname{sink}(\mathrm{cd})$

Notes:

- Reaction 21 was initially treated as irreversible in the base model (i.e. reactions 21 and 22 were lumped together).

- Reaction 56 was treated as reversible in the base model and extended model. The reaction was treated as irreversible in the minimal model. 
- Reaction 77 describes utilization of ATP for cellular processes not captured in the rest of the model.

- Reaction 89. The biomass composition reported in the genome-scale model by Lee et al. (2008) was used for the biomass reaction.

- Reaction 90. The net effect of this reaction is the exchange of intracellular $\mathrm{CO}_{2}$ for an unlabeled $\mathrm{CO}_{2}$ without affecting intracellular carbon balances. This reaction captures endogenous production of unlabeled $\mathrm{CO}_{2}$, for example, due to metabolism of unlabeled biomass metabolites.

- Reaction 91. This reaction captures the uptake and metabolism of unlabeled acetate that was present in our growth medium. The net effect of this reaction is the exchange of intracellular AcCoA for an unlabeled AcCoA without affecting intracellular carbon balances. 


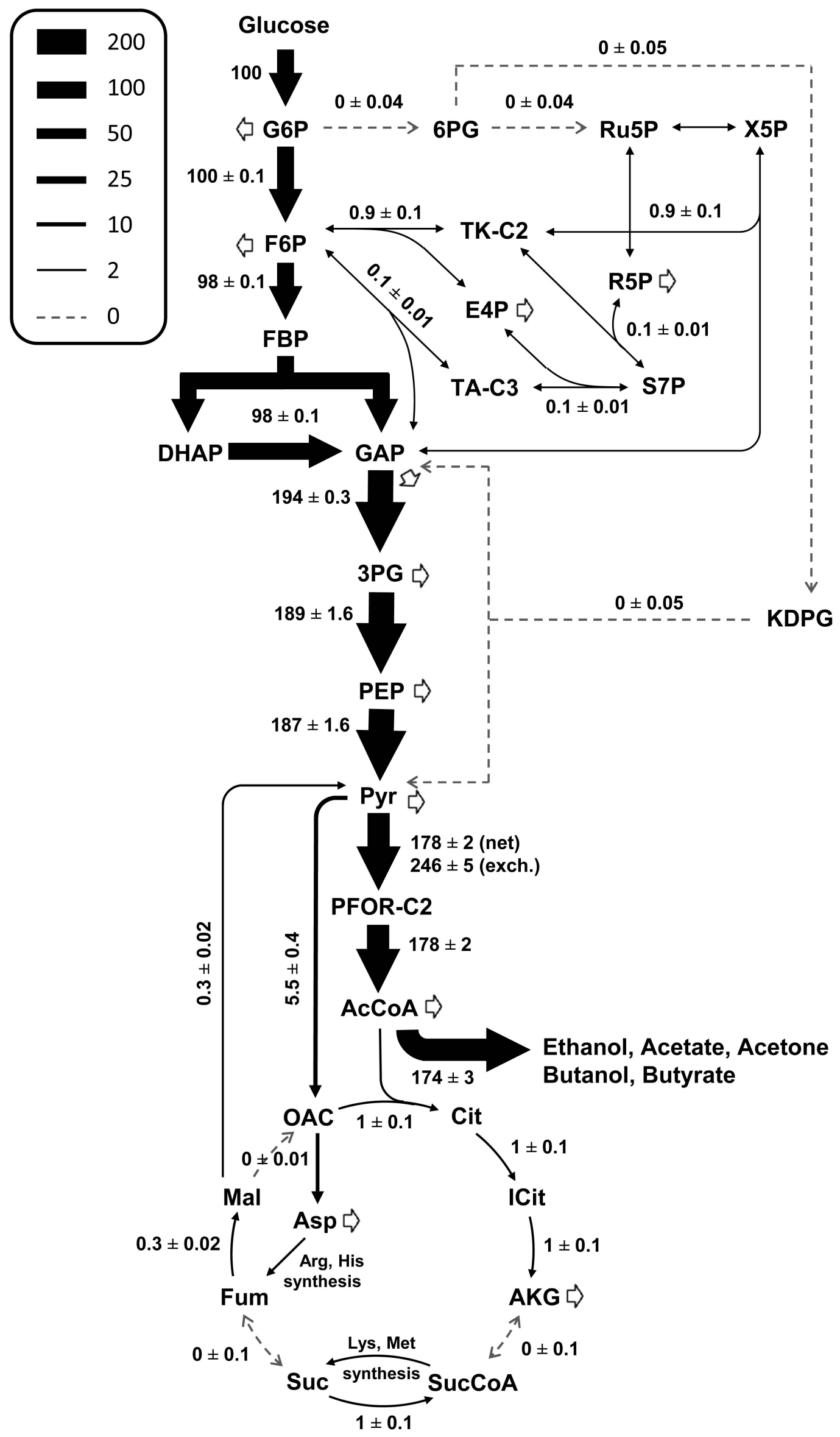


[4- $\left.{ }^{13} \mathrm{C}\right]$ Aspartate

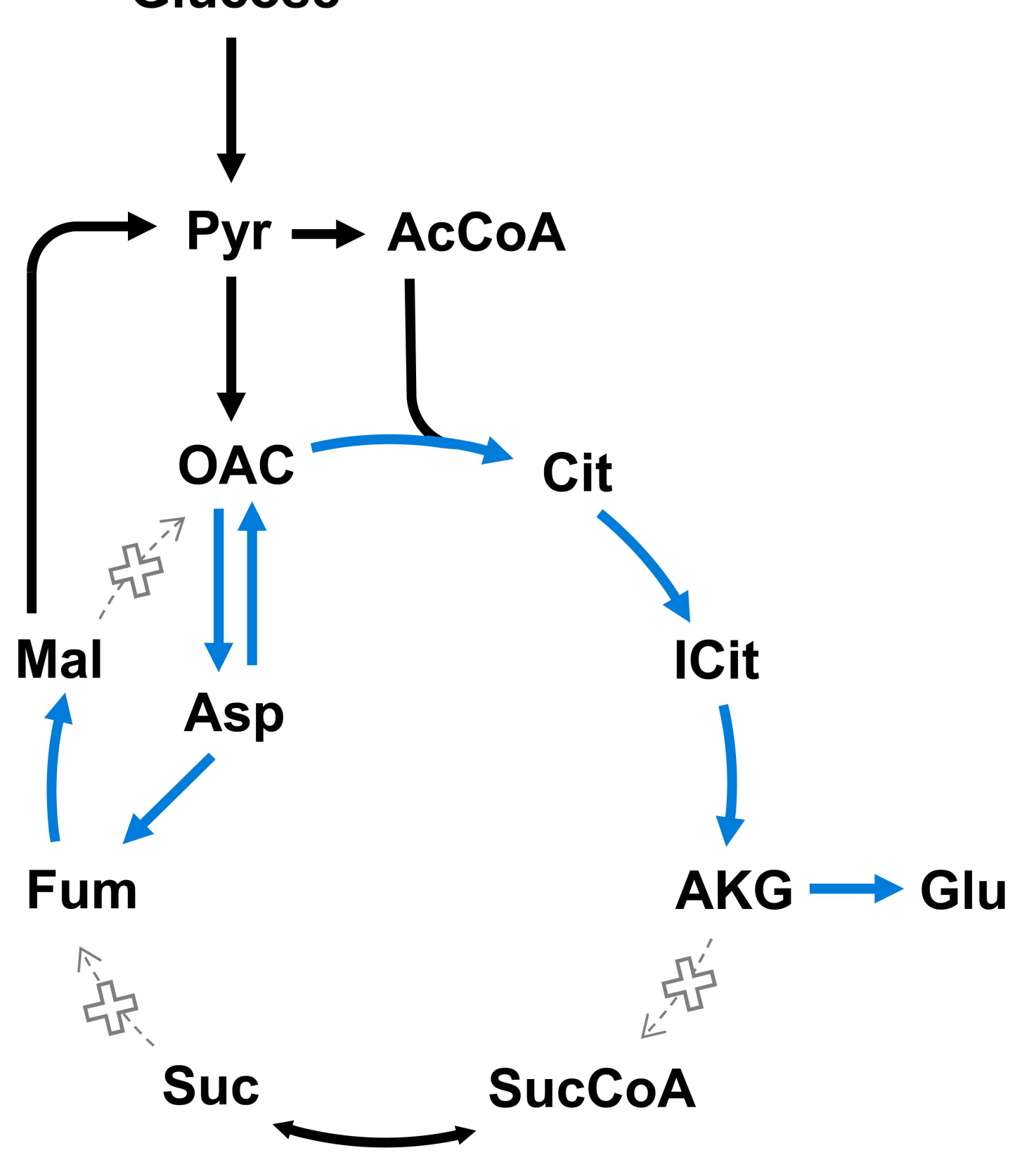

B

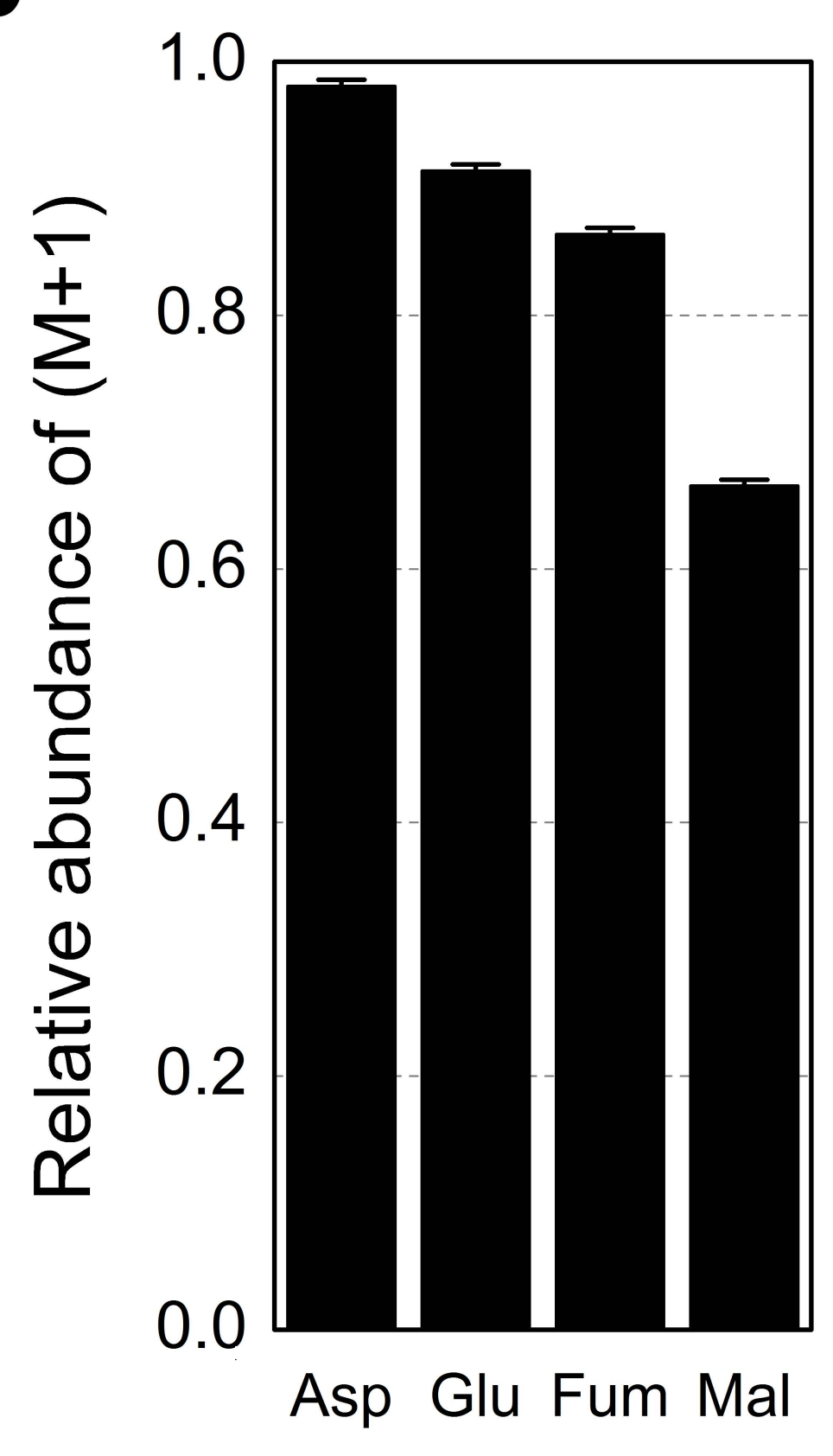

$\left[\mathrm{U}-{ }^{13} \mathrm{C}\right]$ Fumarate

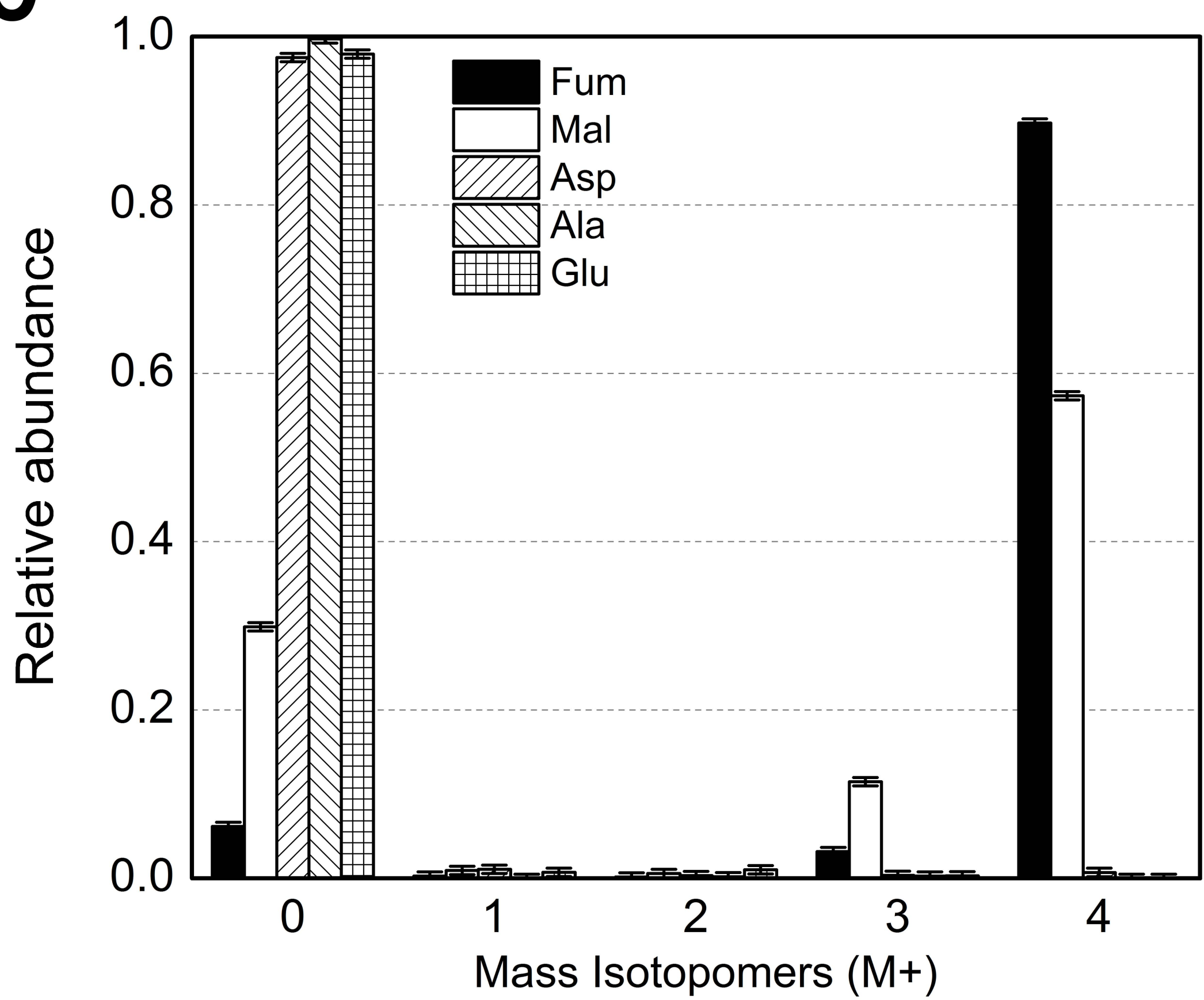




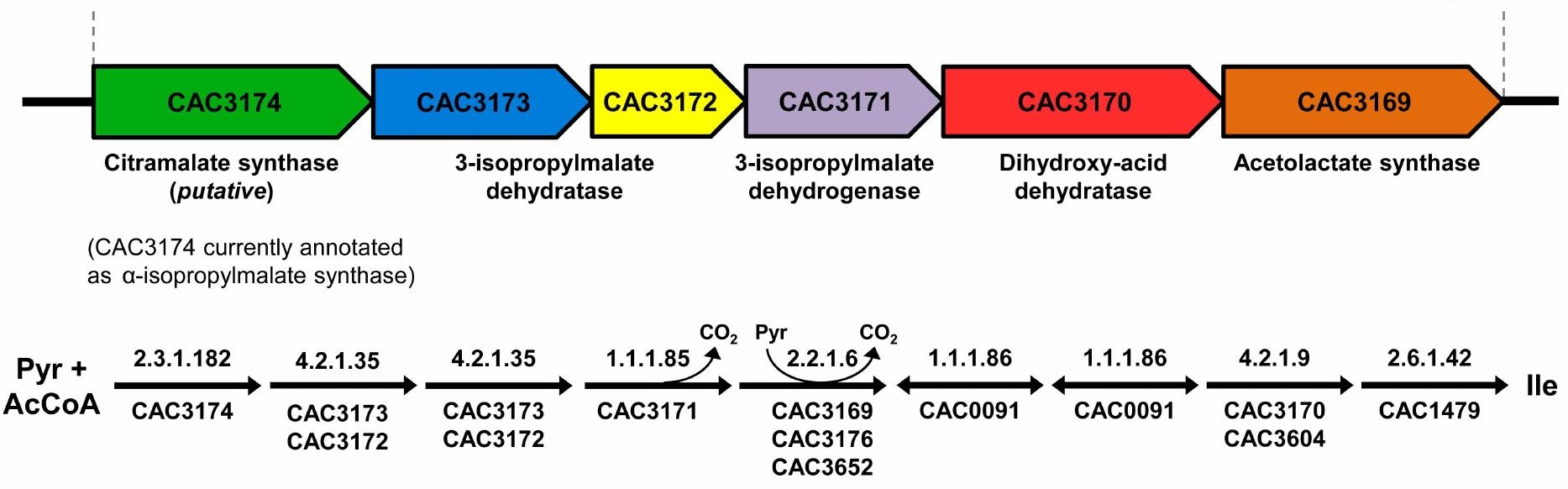




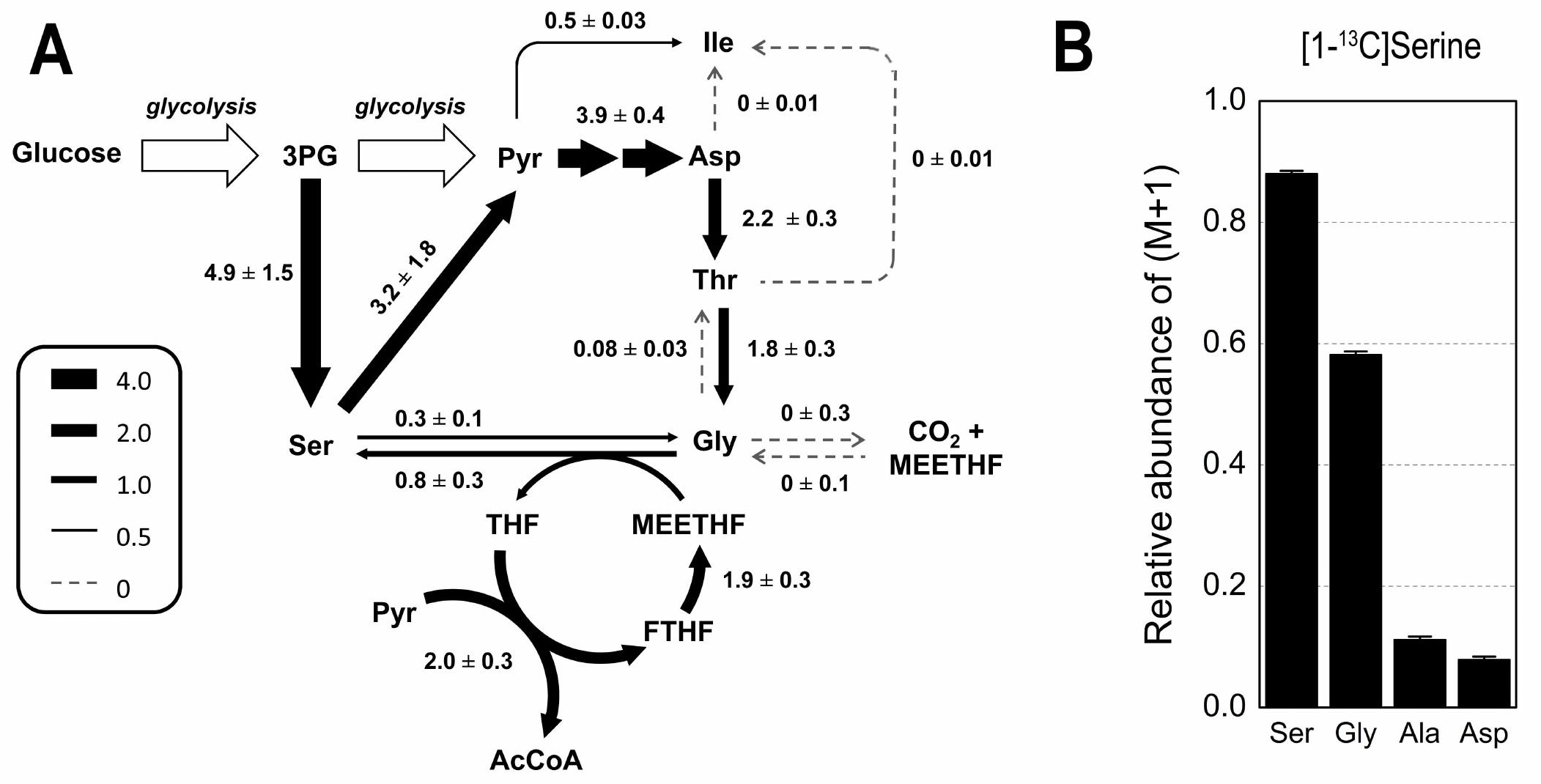

